\title{
The Comparison Among Antibacterial Activity of Mespilus germanica Extracts and Number of Common Therapeutic Antibiotics "In Vitro"
}

\author{
Farideh Tabatabaei-Yazdi, ${ }^{1, *}$ Behrooz Alizadeh-Behbahani, ${ }^{1}$ and Hossein Zanganeh ${ }^{1}$ \\ ${ }^{1}$ Department of Food Sciences and Technology, Faculty of Agriculture, Ferdowsi University of Mashhad, Mashhad, IR Iran \\ ${ }^{*}$ Corresponding author: Farideh Tabatabaei-Yazdi, Department of Food Sciences and Technology, Faculty of Agriculture, Ferdowsi University of Mashhad, Mashhad, IR Iran. \\ E-mail:tabatabai@um.ac.ir
}

Received 2014 July 11; Accepted 2014 August 5.

\begin{abstract}
Background:Antibiotic resistance is a serious and growing phenomenon in contemporary medicine and has emerged as one of the preeminent public health concerns of the $21^{\text {st }}$ century.

Objectives: In this study, antibacterial activity of Mespilus germanica extract against some pathogenic bacterial strains (Streptococcus pyogene, Listeria innocua, Enterobacter aerogenes and Klebsiella pneumoniae) was evaluated.

Materials and Methods: In this experimental study, maceration extraction method was used for M. germanica extract. Disk diffusion method was used to evaluate the antimicrobial effect and broth microdilution method was used to determine the minimum inhibitory concentration and minimum bactericidal concentration. Then, the data were entered into the SPSS-18 statistical software and analyzed using one-way ANOVA and Tukey test.

Results: Antimicrobial activity was assessed by inhibition diameters which were found to range from 8 to $21.5 \mathrm{~mm}$ for the two extracts against all the bacterial strains tested. The minimum inhibitory concentrations (MIC) for the extracts were later determined by three fold serial dilutions method and they ranged 2 - $64 \mathrm{mg} / \mathrm{mL}$ against all the strains and minimum bactericidal concentrations (MBC) for the extracts were later determined by three fold serial dilutions method and they ranged $4-128 \mathrm{mg} / \mathrm{mL}$ against all the strains.

Conclusions: The M. germanica extract showed the more effective impact on the growth S. pyogene and L. innocua than E. aerogenes and K. pneumoniae $(\mathrm{P}<0.05)$. M. germanica in comparison with common therapeutic antibiotics had more inhibitory effect on some of the studied strains in vitro.
\end{abstract}

Keywords: Antibiotic Resistance, Antimicrobial Agents, Pathogenic Bacteria, Mespilus germanica

\section{Background}

For a long period of time, plants have been a valuable source of natural products for maintaining human health. The use of plant extracts and phytochemicals, both with known antimicrobial properties, can be of great significance in therapeutic treatments [1]. Lately, there has been growing interest in the development of newer, natural and broader spectrum of antimicrobial agents due to the likelihood that these phytochemicals will find their way into antimicrobial drugs, the public's increasing awareness of problems associated with the abuse of traditional antibiotics leading to rapid development of resistance against chemical antibiotics by bacterial strains [2].

The Mespilus germanica was already being cultivated about three thousand years ago in the Caspian Sea region of northern Iran and Azerbaijan. M. germanica L. belongs to Rosaceae family and it grows mainly in frost-free areas and on rocks and poor soils. M. germanica, known as the medlar or common medlar, is a large shrub or small tree and the name of the fruit of this tree. In Iran, they are abundant particularly in Guilan and Mazandaran province. The fruits are used as a nutrition component by the local population and are prepared by the local people as marmalade or pickle. The fruit is consumed as a medicinal remedy for example treatment of constipation, diuretic and to rid the kidney and bladder of stones in Iran [3].

Klebsiella pneumoniae organisms are often resistant to multiple antibiotics. Current evidence implicates plasmids as the primary source of the resistance genes. Klebsiella with the ability to produce extended-spectrum beta-lactamases ESBL is resistant to many classes of antibiotics. The most frequent resistances include resistance to aminoglycosides, fluoroquinolones, tetracyclines, chloramphenicol and trimethoprim/sulfamethoxazole [4]. Enterobacter aerogenes is a nosocomial and pathogenic bacterium that causes opportunistic infections including most types of infections. The majority is sensitive to most antibiotics designed for this bacteria class, but this is complicated by their inducible resistance mechanisms,

Copyright (C) 2015, Zahedan University of Medical Sciences. This is an open-access article distributed under the terms of the Creative Commons Attribution-NonCommercial 4.0 International License (http://creativecommons.org/licenses/by-nc/4.0/) which permits copy and redistribute the material just in noncommercial usages, provided the original work is properly cited. 
Tabatabaei-Yazdi F et al.

particularly lactamase which means that they quickly become resistant to standard antibiotics during treatment, requiring change in antibiotic to avoid worsening of the sepsis [5]. Streptococcus pyogene can also cause disease in the form of post infectious "nonpyogenic" (not associated with local bacterial multiplication and pus formation) syndromes. These autoimmune-mediated complications follow a small percentage of infections and include rheumatic fever and acute post-infectious glomerulo-nephritis [6]. Listeria innocua is important because it is very similar to the food-borne pathogen Listeria monocytogenes but non-pathogenic in character [7].

Antibiotic resistance is a serious and growing phenomenon in contemporary medicine and has emerged as one of the pre-eminent public health concerns of the $21^{\text {st }}$ century, in particular as it pertains to pathogenic organisms. A world health organization (WHO) report released 2014 states, this serious threat is no longer a prediction for the future and it is happening right now in every region of the world and has the potential to affect anyone, of any age, in any country. Antibiotic resistance when bacteria change so antibiotics no longer work in people who need them to treat infections is now a major threat to public health [2].

\section{Objectives}

The aim of this study is to investigate the antimicrobial effect of M. germanica on Streptococcus pyogenes PTCC 1447, L. innocua ATTC 33090, E. aerogenes ATTC 13048 and K. pneumoniae PTCC 1053 and its comparison with common therapeutic antibiotics.

\section{Materials and Methods}

This experimental study was conducted at industrial microbiology laboratory, department of food science and technology, Ferdowsi University of Mashhad in 2014.

Microorganisms and culture media: Four bacteria were tested in this study and include S. pyogenes PTCC 1447, L. innocua ATTC 33090, E. aerogenes ATTC 13048 and K. pneumoniae PTCC 1053. All culture media were purchased from Merck (Germany). Microorganisms were grown overnight on trypticase soy broth (TSB), under optimal conditions. Overnight cultures were adjusted to match a 0.5 McFarland standard and further diluted 1:100 with Mueller-Hinton broth (MHB). The dilution obtained served as the inoculums for antibacterial activity assay [8].

\subsection{Preparation of the Plant}

The M. germanica were collected from countryside of Aliabad-e-Katul (Golestan province, Iran) and dried at room temperature. Samples were crashed and transferred into glass container and preserved until extraction procedure was performed in the laboratory and taxonomic identification was performed by the faculty of science herbarium, Ferdowsi university of Mashhad, Mashhad, Iran [9].

\subsection{Suspension Preparation}

Fresh cultivated S. pyogenes PTCC 1447, L. innocua ATTC 33090, E. aerogenes ATTC 13048 and K. pneumoniae PTCC 1053 colonies were suspended in $5 \mathrm{~mL}$ of $0.85 \%$ normal saline. Suspension was mixed for 15 seconds with a vortex (Germany). Then its concentration was adjusted to $1.5 \times$ $10^{8} \mathrm{CFU} / \mathrm{mL}$ based on a standard 0.5 McFarland [10].

\subsection{Extract Preparation}

The M. germanica were pulverized into a coarse powder and $25 \mathrm{~g}$ grinded powder was soaked in $125 \mathrm{~mL}$ ethanol $96^{\circ}$ (Merck-Germany) or water, for 24 hours (shaking occasionally with a shaker). After one day of dissolving process, materials were filtered (Whatman no. 1 filter paper) and centrifuged in $9000 \mathrm{~g}$ for 15 minutes. Then extracts were evaporated using rotary evaporator and dried extracts were obtained and stored at $4^{\circ} \mathrm{C}$ in air tight screwcap tube [11].

\subsection{Antibiotics Susceptibility Test}

The test was done by using the agar disk diffusion method or the Kirby-Bauer method as recommended by the national committee for clinical laboratory standard (NCCLS) on bacterial strains of S. pyogenes PTCC 1447, L. innocua ATTC 33090, E. aerogenes ATTC 13048 and K. pneumoniae PTCC 1053. The antibiotic discs used in this test are erythromycin, ampicillin, gentamicin, ciprofloxacin, clindamycin and vancomycin. To perform this test, the accurate identification of species of bacteria, S. pyogenes, L. innocua, E. aerogenes and K. pneumoniae colonies of strains tested in Mueller Hinton broth (MHB) and then suspended in standard 0.5 McFarland was conducted to compare. If turbidity ensures it matches perfectly sterile cotton swab using four different bacteria in the culture medium Mueller Hinton agar (MHA) has cultivated and antibiotic discs used in sterile conditions with respect to the distance of two centimeters away from each other placed on medium Mueller Hinton agar plates. After incubation for 18 to 24 hours at $37^{\circ} \mathrm{C}$, the results obtained with the standard provided by the national committee for clinical laboratory standards were compared to susceptible and resistant $[12,13]$.

\subsection{Determining Antimicrobial Activities Using the Disc Diffusion Method}

The agar disc diffusion method was employed to determine antimicrobial activity in this study. In the disk agar diffusion method $1.5 \times 10^{8} \mathrm{CFU} / \mathrm{mL}$ (equivalent to 0.5 McFarland standards) of standard culture of each strain was cultured on agar surface at the first step, and then it was spread on the surface of agar by sterile glass spreader. After the inoculated plates had dried sufficiently the discs were kept over the agar plates using sterile forceps at various concentrations $(10,20,30$, and $40 \mathrm{mg} / \mathrm{mL})$ [14]. 


\subsection{Determining Antimicrobial Activities Using the Pour Plate Method}

The pour plate technique can be used to determine the number of microbes/mL in a specimen. It has the advantage of not requiring previously prepared plates and is often used to assay bacterial contamination of foodstuffs. Ethanol extract $(0.2 \mathrm{~g})$ were added to $5 \mathrm{~mL}$ of sterile distilled water. After that, it was stirred with vortex system to assist being steady, subsequently $1 \mathrm{~mL}$ of this solution was added to sterile plates. The final concentration of the extract was 2 $\mathrm{mg} / \mathrm{mL}$. At the next step, the sterilized Mueller Hinton agar (Merck-Germany) medium were added to the plates and placed at room temperature. One loop of each standard strain culture media was cultured inoculums on these medium. The plates were incubated for 24 hours at $37^{\circ} \mathrm{C}$ [15].

\subsection{Minimum Inhibitory Concentration (MIC)}

The lowest concentration (highest dilution) of test agent preventing appearance of turbidity (growth) is considered to be the minimal/minimum inhibitory concentration (MIC). At this dilution the test agent is bacteriostatic. Serial dilution method was determined MIC. Various concentrations $(2,4,8,16,32,64,128,256 \mathrm{mg} / \mathrm{mL})$ of extracts were prepared in $10 \mathrm{~cm}$ experimental tubes. Each tube contained $9 \mathrm{~mL}$ of Muller Hilton was sterilize by autoclaving. After cooled, $1 \mathrm{~mL}$ of different concentrations $(2,4,8,16,32,64$, $128,256 \mathrm{mg} / \mathrm{mL}$ ) of each extract was added to each tube. The tubes were incubated for 24 hours at $37^{\circ} \mathrm{C}$. The lowest concentration that did not permit any visible growth when compared with the control was considered as the minimum inhibitory concentration [16].

\subsection{Minimum Bactericidal Concentration (MBC)}

The minimum bactericidal concentration (MBC) or the minimum lethal concentration (MLC) of an antibacterial which is defined as the maximum dilution of the product that will kill a test organism can be determined by sub-culturing last clear MIC tube onto growth medium and examining for bacterial growth. Serial dilutions are made of the products in bacterial growth media. MBC was determined according to agar dilution method with slight modifications. The MBC were determined by incorporating various concentrations of extracts $(2,4,8,16,32,64,128,256 \mathrm{mg} / \mathrm{mL})$ in Muller Hilton Broth for bacteria [17].

\subsection{Statistical Analysis}

The experimental results were expressed by means \pm standard deviation. The data were analyzed using one way analysis of variance (ANOVA) using SPSS-18. In the one-way ANOVA, we have tested the values of a quantitative variable in the different groups.

\section{Results}

The results of the antimicrobial effects of ethanolic and aqueous extracts, by pour plate method were showed 2 $\mathrm{mg} / \mathrm{mL}$ concentration of ethanolic extract, were quite effective on reduce of growth $S$. pyogenes, L. innocua, E. aerogenes and K. pneumonia; and were had prevent growth over the medium. The aqueous extract, only had antimicrobial effect in $2 \mathrm{mg} / \mathrm{mL}$ concentration on growth of, S. pyogenes and L. innocua.

The results the antimicrobial effects of ethanolic and aqueous $M$. germanica extracts, by the agar diffusion method were presented in Table 1 . The results the antimicrobial effects of common therapeutic antibiotics, by Kirby-Bauer method were presented in Table 2 . The results of MIC and MBC of ethanolic and aqueous M. germanica extracts were presented in Tables 3 and 4.

Table 1. Average Diameter (mm) of Microbial Free Zone Area of Aqueous and Ethanolic M. germanica Extracts Concentrations on $S$. pyogenes, L. innocua, E. aerogenes and K. pneumonia (Disk Agar Diffusion Method) ${ }^{\mathrm{a}}$

\begin{tabular}{|c|c|c|c|c|c|}
\hline \multirow[t]{2}{*}{ Microorganism } & \multirow[t]{2}{*}{ Type of Extract } & \multicolumn{4}{|c|}{ The Concentration of $M$. germanica Extracts, $\mathrm{mg} / \mathrm{mL}$} \\
\hline & & 10 & 20 & 30 & 40 \\
\hline S.pyogenes & Aqueous & $10.90 \pm 0.58$ & $14.10 \pm 0.57$ & $17.50 \pm 0.55$ & $20.00 \pm 0.28$ \\
\hline L. innocua & Aqueous & $9.60 \pm 0.58$ & $13.10 \pm 0.57$ & $15.70 \pm 0.55$ & $18.80 \pm 0.28$ \\
\hline E. aerogenes & Aqueous & $8.00 \pm 0.58$ & $10.50 \pm 0.58$ & $13.10 \pm 0.28$ & $16.00 \pm 0.53$ \\
\hline K. pneumonia & Aqueous & $9.20 \pm 0.58$ & $12.40 \pm 0.58$ & $15.40 \pm 0.28$ & $18.00 \pm 0.53$ \\
\hline S.pyogenes & Ethanolic & $12.90 \pm 0.58$ & $15.10 \pm 0.57$ & $19.50 \pm 0.55$ & $21.50 \pm 0.28$ \\
\hline L. innocua & Ethanolic & $11.60 \pm 0.58$ & $15.10 \pm 0.57$ & $17.70 \pm 0.55$ & $21.00 \pm 0.28$ \\
\hline E. aerogenes & Ethanolic & $10.00 \pm 0.58$ & $12.50 \pm 0.58$ & $15.10 \pm 0.28$ & $17.70 \pm 0.53$ \\
\hline K. pneumonia & Ethanolic & $10.80 \pm 0.58$ & $13.20 \pm 0.58$ & $16.30 \pm 0.28$ & $18.90 \pm 0.53$ \\
\hline
\end{tabular}

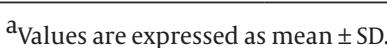


Table 2. Average Diameter (mm) of Microbial Free Zone Area of Common Therapeutic Antibiotics, by Kirby-Bauer Method on $S$. pyogenes, L. innocua, E. aerogenes and K. pneumonia

\begin{tabular}{lcccccc}
\hline Microorganism & Vancomycin & Ciprofloxacin & \multicolumn{4}{c}{ Antibiotics } \\
\cline { 3 - 7 } & & & Ampicillin & Gentamicin & Clindamycin & Erythromycin \\
\hline S. pyogenes & 8 & 24 & 8 & 14 & 8 & 10 \\
L. innocua & 7 & 21 & 8 & 13 & 12 & 11 \\
E. aerogenes & 7 & 16 & 7 & 15 & 16 & 9 \\
K. pneumonia & 9 & 18 & 7 & 14 & 14 & 10 \\
\hline
\end{tabular}

Table 3. Minimum Inhibitory Concentration (MIC) of Aqueous and Ethanolic Extract of M. germanica on S. pyogenes, L. innocua, E. aerogenes and K. pneumonia ${ }^{\mathrm{a}}$

\begin{tabular}{|c|c|c|c|c|c|c|c|c|c|c|c|}
\hline \multirow[t]{2}{*}{ Bacteria Species } & \multirow[t]{2}{*}{ Type of Extract } & \multicolumn{10}{|c|}{ Concentration, $\mathrm{mg} / \mathrm{mL}$} \\
\hline & & 2 & 4 & 8 & 16 & 32 & 64 & 128 & 256 & Negative & Positive \\
\hline S. pyogenes & Aqueous & + & - & - & - & - & - & - & - & - & + \\
\hline L.innocua & Aqueous & + & + & - & - & - & - & - & - & - & + \\
\hline E. aerogenes & Aqueous & + & + & + & + & + & - & - & - & - & + \\
\hline K. pneumonia & Aqueous & + & + & + & + & - & - & - & - & - & + \\
\hline S. pyogenes & Ethanolic & - & - & - & - & - & - & - & - & - & + \\
\hline L.innocua & Ethanolic & + & - & - & - & - & - & - & - & - & + \\
\hline E. aerogenes & Ethanolic & + & + & + & + & - & - & - & - & - & + \\
\hline K. pneumonia & Ethanolic & + & + & + & + & - & - & - & - & - & + \\
\hline
\end{tabular}

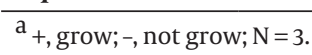

Table 4. Minimum Bactericidal Concentration (MBC) of Aqueous and Ethanolic Extract of M. germanica on S. pyogenes, L.innocua,E. aerogenes and K. pneumonia ${ }^{\mathrm{a}}$

\begin{tabular}{|c|c|c|c|c|c|c|c|c|c|c|c|}
\hline \multirow[t]{2}{*}{ Bacteria Species } & \multirow[t]{2}{*}{ Type of Extract } & \multicolumn{10}{|c|}{ Concentration, $\mathrm{mg} / \mathrm{mL}$} \\
\hline & & 2 & 4 & 8 & 16 & 32 & 64 & 128 & 256 & Negative & Positive \\
\hline S. pyogenes & Aqueous & + & + & - & - & - & - & - & - & - & + \\
\hline L. innocua & Aqueous & + & + & + & - & - & - & - & - & - & + \\
\hline E. aerogenes & Aqueous & + & + & + & + & + & + & - & - & - & + \\
\hline K.pneumonia & Aqueous & + & + & + & + & + & - & - & - & - & + \\
\hline S. pyogenes & Ethanolic & + & - & - & - & - & - & - & - & - & + \\
\hline L.innocua & Ethanolic & + & + & - & - & - & - & - & - & - & + \\
\hline E. aerogenes & Ethanolic & + & + & + & + & + & - & - & - & - & + \\
\hline К. pneumonia & Ethanolic & + & + & + & + & + & - & - & - & - & + \\
\hline
\end{tabular}

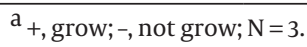

\section{Discussion}

According to the result of this study, antimicrobial activity was assessed by inhibition diameters which were found to range from $8-21.5 \mathrm{~mm}$ for the two extracts against all the bacterial strains tested. The M. germanica extract showed the more effective impact on the growth $S$. pyogene and L. innocua than E. aerogenes and K. pneumoniae. The results showed $2 \mathrm{mg} / \mathrm{mL}$ concentration of ethanolic extract, were quite effective on reduce of growth S. pyogenes, L. innocua, E. aerogenes and K. pneumonia and were had prevent growth over the medium. The aqueous extract, only had antimicrobial effect in $2 \mathrm{mg} / \mathrm{mL}$ concen- tration on growth of, S. pyogenes and L. innocua.

Many plant extracts owe their potency to the presence of substances such as tannins, phenolics, micro elements, essential oils, peptides, unsaturated long chain aldehydes, alkaloids and so on. These substances are usually found in various parts of the plants like roots, leaves, shoots and bark [18]. Many plants have therefore become sources of important drugs and the pharmaceutical industries have come to consider them as a source of bioactive agents that can be used in the preparation of synthetic medicine [19]. 
The results of the present study clearly showed that $M$. germanica extracts showed antibacterial activity against tested pathogenic bacterial strains including antibiotic resistant strains. The effectiveness of the active compounds present in plant extracts cause the production of growth inhibition zones that appear as clear areas surrounding the disk. Antibacterial activity may be due to active components which are present in plant extracts. However, some plant extracts were unable to exhibit antibacterial activity against tested bacterial strains. These bacterial strains may have some kind of resistance mechanisms e.g. enzymatic inactivation, target sites modification and decrease intracellular drug accumulation [20] or the concentration of the compound used may not be sufficient. No inhibition was observed with controls, which proves that solvents could not act as antibacterial agents. Further investigations were done using extracts of $M$. germanica only, since they showed considerable antibacterial activity. In almost all tests, ethanol extract showed better inhibition against all tested bacterial strains, indicating that active ingredients in plant materials could be extracted into ethanol. However, highest antibacterial activity was observed against S. pyogenes.

On the basis of the above results, it showed that ethanol extract of M. germanica exhibited a greater inhibition compared with aqueous extract. Parekh et al. reported that most of the antimicrobial active compounds were soluble in polar solvent such as alcohol instead of water [21]. This result is comparable to the study by de Souza et al. using alcohol extract of L. sibiricus that showed effective antibacterial activity on Bacillus subtilis [22]. Bajwa and Shafique showed that methanol fraction of $A$. rabiei exhibited more promising results in suppressing the fungal growth rather than aqueous extract [23]. This was also reported by Zafar et al. where chloroform extract of Melia azedarch leaves was active against Fusarium chamdosporum while water extract of the leaves did not show any positive results [24].

In this study, by increasing the amount of alcoholic extract on disc diffusion method, inhibition zone around the disc was increased. Various sizes of inhibition zones were measured by a ruler in millimeters. The maximum size of inhibition zone for M. germanica ethanol extract in the disc method was $21.5 \mathrm{~mm}(40 \mathrm{mg} / \mathrm{mL})$ and M. germanica aqueous extract was $20 \mathrm{~mm}(40 \mathrm{mg} / \mathrm{mL})$, respectively. The results show that ethanolic and aqueous extract of $M$. germanica in all concentrations $(10,20,30$ and $40 \mathrm{mg} / \mathrm{mL})$ had the inhibitory effect on S. pyogenes, L. innocua, E. aerogenes and K. pneumonia.

The results of MIC and MBC assay revealed that M. germanica have more antibacterial effect on Gram-positive bacteria compared to Gram-negative bacteria. So that Gram-positive bacteria such as S. pyogenes and L. innocua and Gram-negative bacteria such as E. aerogenes and K. pneumonia showed lowest and highest MIC, respectively. The MIC of ethanolic extract of M. germanica for $S$. pyogenes, L. innocua, E. aerogenes and K. pneumonia were 2, 4, 32 and $32 \mathrm{mg} / \mathrm{mL}$, respectively. But MIC of the aque- ous extract of M. germanica for S. pyogenes, L. innocua, E. aerogenes and $K$. pneumonia were 4, 8, 64 and $32 \mathrm{mg} / \mathrm{mL}$, respectively. The MBC of ethanolic extract of M.germanica for S. pyogenes, L. innocua, E. aerogenes and K. pneumonia were $4,8,64$ and $64 \mathrm{mg} / \mathrm{mL}$, respectively. But MBC of the aqueous extract of $M$. germanica for S. pyogenes, L. innocua, E. aerogenes and K. pneumonia were 8, 16, 128 and $64 \mathrm{mg} /$ $\mathrm{mL}$, respectively. This is probably due to presence of lipopolysaccharide in cell wall of Gram-negative bacteria. Lipopolysaccharides of cell wall can prevent influx of active compounds to cytoplasmic membrane of these bacteria [25]. In study of Khalil and Li reported the sage essential oil was effective against both Gram positive (Streptococcus) and Gram negative bacteria (E. coli, S. typhi) and the antibacterial effect against Gram positive bacteria was more than Gram negative bacteria which had similar result with this study [26]. Arias et al. investigated the antibacterial effects of aqueous and ethanolic extract of Acacia aroma They reported that Gram positive bacteria (Bacillus cereus and Bacillus Subtlis) are more sensitive than Gram negative bacteria (Escherichia coli) to plant extracts. This result is consistent with the findings of this study [27]. Also, they reported that ethanolic extract compared to the aqueous extract was more effective and has a greater inhibitory effect [27]. These results are consistent with reported by Karsha and Laskhmi, that Piper nigrum L. extract is more susceptible to Gram positive compared against Gram negative. It might because P. nigrum L. extract altered the membrane permeability results in the leakage of nucleic acid and protein into the extracellular medium [28]. The results of this study provide informative data for the use of the extracts from M. germanica against bacterial microbial infections. However, the clinical application of this plant are needed more and larger studies and if successful and standardization of results. These plants can use as an alternative instead of inert and ineffective anti microbial drugs currently used.

\section{Acknowledgments}

The authors wish to express their profound gratitude and thank sincerely to research's deputy of Ferdowsi University of Mashhad for providing the cost of this project and help to implementation of this project with code 2/29987 which adopted of the research council of agricultural faculty. The authors wish to express their profound gratitude to Ms. Afsharian who helps about experiments.

\section{Footnote}

Funding/Support:Ferdowsi University of Mashhad.

\section{References}

1. Shaik G, Sujatha N, Mehar SK. Medicinal plants as source of antibacterial agents to counter Klebsiella pneumoniae. J Appl Pharm Sci. $2014 ; 4(1): 135$.

2. Dorman HJ, Deans SG. Antimicrobial agents from plants: antibacterial activity of plant volatile oils. J Appl Microbiol. 2000;88(2):308-16. [PubMed:10736000] 
3. Ayaz FA, Demir O, Torun H, Kolcuoglu Y, Colak A. Characterization of polyphenoloxidase (PPO) and total phenolic contents in medlar (Mespilus germanica L.) fruit during ripening and over ripening. Food Chem. 2008;106(1):291-8. doi: 10.1016/j.foodchem.2007.05.096.

4. Paterson DL, Ko WC, Von Gottberg A, Mohapatra S, Casellas JM, Goossens H, et al. Antibiotic therapy for Klebsiella pneumoniae bacteremia: implications of production of extendedspectrum beta-lactamases. Clin Infect Dis. 2004;39(1):31-7. doi: 10.1086/420816. [PubMed:15206050]

5. Brown AN, Smith K, Samuels TA, Lu J, Obare SO, Scott ME. Nanoparticles functionalized with ampicillin destroy multipleantibiotic-resistant isolates of Pseudomonas aeruginosa and Enterobacter aerogenes and methicillin-resistant Staphylococcus aureus. Appl Environ Microbiol. 2012;78(8):2768-74. doi: 10.1128/ AEM.06513-11. [PubMed: 22286985]

6. Albrich WC, Monnet DL, Harbarth S. Antibiotic selection pressure and resistance in Streptococcus pneumoniae and Streptococcus pyogenes. Emerg Infect Dis. 2004;10(3):514-7. doi: 10.3201/ eid1003.030252. [PubMed:15109426]

7. Coma V, Sebti I, Pardon P, Deschamps A, Pichavant FH. Antimicrobial edible packaging based on cellulosic ethers, fatty acids, and nisin incorporation to inhibit Listeria innocua and Staphylococcus aureus.J Food Prot. 2001;64(4):470-5. [PubMed: 11307881]

8. Fitzgerald DJ, Stratford M, Gasson MJ, Ueckert J, Bos A, Narbad A Mode of antimicrobial action of vanillin against Escherichia coli, Lactobacillus plantarum and Listeria innocua. J Appl Microbiol. 2004;97(1):104-13. doi: 10.1111/j.1365-2672.2004.02275.x. [PubMed: 15186447]

9. Raybaudi-Massilia RM, Mosqueda-Melgar J, Martin-Belloso O. Antimicrobial activity of essential oils on Salmonella enteritidis, Escherichia coli, and Listeria innocua in fruit juices. J Food Prot. 2006;69(7):1579-86. [PubMed:16865889]

10. Francis GA, O'Beirne D. Effects of vegetable type and antimicrobial dipping on survival and growth of Listeria innocua and $\mathrm{E}$. coli. Int j food sci technol. 2002;37(6):711-8.

11. Mosafa E, Yahyaabadi S, Doudi M. In-Vitro Antibacterial Properties of Sage (Salvia officinalis) Ethanol Extract against Multidrug Resistant Staphylococcus aureus, Escherichia coli, Pseudomonas aeruginosa and Klebsiella pneumoniae. Zahedan J Res Med Sci. 2014;16(10):42-6.

12. Velickovic DT, Randelovic NV, Ristic MS, Velickovic AS, Smelcerovic AA. Chemical constituents and antimicrobial activity of the ethanol extracts obtained from the flower, leaf and stem of Salvia officinalis L. J Serbian Chem Soc. 2003;68(1):17-24. doi: 10.2298| JSC0301017V.

13. Abu-Shanab B, Adwan G, Abu-Safiya D, Jarrar N, Adwan K. Antibacterial activities of some plant extracts utilized in popular medicine in Palestine. Turk J Biol. 2004;28(99):102.

14. Swenson JM, Killgore GE, Tenover FC. Antimicrobial susceptibility testing of Acinetobacter spp. by NCCLS broth microdilution and disk diffusion methods. J Clin Microbiol. 2004;42(11):5102-8.
doi:10.1128/JCM.42.11.5102-5108.2004. [PubMed:15528702]

15. Leonardo MR, da Silva LA, Tanomaru Filho M, Bonifacio KC, Ito IY. In vitro evaluation of antimicrobial activity of sealers and pastes used in endodontics. J Endod. 2000;26(7):391-4. [PubMed: 11199762]

16. Kahlmeter G, Brown DF, Goldstein FW, MacGowan AP, Mouton JW, Osterlund A, et al. European harmonization of MIC breakpoints for antimicrobial susceptibility testing of bacteria. J Antimicrob Chemother. 2003;52(2):145-8. doi: 10.1093/jac/dkg312. [PubMed: 12837738]

17. Kumari AA, Promwichit P. In vitro antimicrobial evaluation of Zingiber officinale, Curcuma longa and Alpinia galanga extracts as natural food preservatives. Am J Food Technol. 2009;4(5):192200. doi:10.3923/ajft.2009.192.200.

18. Subashini R, Mahesh V, Kavitha A, Geethanjali B, Umamaheshwari S. Comparative Evaluation of Antimicrobial Activity of Selected Three Herbal Plants Extract with Digital Image Processing. Eur J Biol Inform. 2013;9(2):14-26.

19. Rukayadi Y, Lau KY, Zainin NS, Zakaria M, Abas F. Screening antimicrobial activity of tropical edible medicinal plant extracts against five standard microorganisms for natural food preservative. Int Food Res J. 2013;20(5):2905-10.

20. Abeysinghe PD, Pathirana RN, Wanigatunge RP. Evaluation of antibacterial activity of different mangrove plant extracts. Ruhuna j sci. 2012;1(1)

21. Parekh J, Karathia N, Chanda S. Evaluation of antibacterial activity and phytochemical analysis of Bauhinia variegata L. bark. Afr JBiomed Res. 2006;9(1)

22. de Souza GC, Haas AP, von Poser GL, Schapoval EE, Elisabetsky E. Ethnopharmacological studies of antimicrobial remedies in the south of Brazil. J Ethnopharmacol. 2004;90(1):135-43. [PubMed: 14698521]

23. Bajwa R, Shafique S, Shafique S. Fungitoxicity of aqueous and solvent extracts of Datura metel against Ascochyta rabiei. Mycopath. 2008;6(1\&2):17-22.

24. Zafar I, Mussarat S, Farrakh H, Sheraz B, Mohammad I, Shahida $Z$, et al. Antifungal properties of some indigenous plants from Peshawar valley. Asia j plant sci. 2002;2(6):708-9. doi: 10.3923/ ajps.2002.708.709.

25. Takeuchi O, Hoshino K, Kawai T, Sanjo H, Takada H, Ogawa T, et al. Differential roles of TLR2 and TLR4 in recognition of gram-negative and gram-positive bacterial cell wall components. Immunity. 1999;11(4):443-51. [PubMed:10549626]

26. Khalil R, Li ZG. Antimicrobial activity of essential oil of Salvia officinalis L. collected in Syria. Afr J Biotechnol. 2013;10(42):8397-402.

27. Arias ME, Gomez JD, Cudmani NM, Vattuone MA, Isla MI. Antibacterial activity of ethanolic and aqueous extracts of Acacia aroma Gill. ex Hook et Arn. Life Sci. 2004;75(2):191-202. doi: 10.1016/j. lfs.2003.12.007. [PubMed:15120571]

28. Karsha PV, Lakshmi OB. Antibacterial activity of black pepper (Piper nigrum Linn.) with special reference to its mode of action on bacteria. Indian J Nat Prod Resour. 2010;1(2):213-5. 